\title{
X Congreso Ibérico de Agroingeniería

\section{El cultivo asociado de melón-caupí puede mejorar la producción del melón, la productividad del terreno y reducir el uso de fertilizantes}

\author{
J.A. Acosta Avilés ${ }^{1}$, V. Sánchez-Navarro', Ozbolat, O. ${ }^{1}$, S. Martínez-Martínez ${ }^{1}$, R. Zornoza ${ }^{1}$ \\ 1 Universidad Politécnica de Cartagena. Área de Ingeniería Agroforestal (Departamento de Ingeniería \\ Agronómica). Paseo Alfonso XIII, 48.30203 Cartagena (Murcia); ja.acosta@upct.es
}

\begin{abstract}
Resumen: El objetivo de este estudio fue evaluar el efecto de diferentes combinaciones de melón asociado con caupí en el rendimiento y calidad del melón. Bajo manejo ecológico, se compararon el monocultivo de melón con 3 sistemas de cultivo asociado melón-caupí intercalando filas en las proporciones 1:1, 2:1 y mixto (donde en una misma fila se alterna melón y caupí). En las parcelas de estudio se incorporaron residuos de leguminosas como abono verde y se disminuyó la fertilización en un $30 \%$ en los sistemas asociados. Todas las combinaciones de cultivos asociados aumentaron el rendimiento de melón entre un 34-70\%, mientras que el rendimiento comercial fue entre un $40-80 \%$ superior en los sistemas asociados. No se observaron diferencias significativas en los parámetros de calidad del melón, a excepción del contenido de azúcar, que fue ligeramente superior en los melones cultivados en monocultivo. Los valores del LER fueron 1,82; 1,91 y 1,89 para los sistemas 1:1, 2:1 y mixto, respectivamente, destacando el aumento significativo en la productividad de la tierra cuando se intercala el melón con el caupí. Por lo tanto, la introducción de caupí en el cultivo asociado con melón resulta un sistema sostenible, con disminuciones en el uso de fertilizantes a la vez que se aumentaba tanto el rendimiento de melón como el LER, sin efectos negativos significativos en la calidad.
\end{abstract}

Palabras clave: Cucumis melo; Vigna unguiculata; cultivos asociados; manejo ecológico; rendimiento; productividad de la tierra

\section{Introducción}

La inclusión de leguminosas en sistemas de cultivos asociados puede ser una buena alternativa para incrementar tanto la fertilidad del suelo como el contenido de materia orgánica. Las leguminosas mejoran la fertilidad del suelo a través de la fijación biológica de nitrógeno, la cual se produce a través de la simbiosis entre leguminosas y bacterias rizosféricas, como son las $\alpha$ - y $\beta$-proteobacterias con la capacidad de fijar nitrógeno atmosférico [1]. Además, el uso de leguminosas puede favorecer la acumulación de $\mathrm{C}$ y $\mathrm{N}$ en el suelo a través de la producción de biomasa subterránea, tipo y cantidad de exudados de raíces y la estimulación de microorganismos del suelo [2]. Todo ello, reduce la necesidad de aplicar grandes cantidades de fertilizantes nitrogenados [3], favoreciendo indirectamente la reducción de emisiones de gases de efecto invernadero. Finalmente, la introducción de leguminosas asociadas a otros cultivos proporciona otros efectos positivos, como inducir el crecimiento de microorganismos del suelo [4] o incluso reducir la necesidad de pesticidas debido a la diversificación de cultivos [5].

El caupí o judía de careta (Vigna unguiculata L. Walp) es una leguminosa de grano, nativa del sur de África, aunque es consumida ampliamente en todo el mundo [6]. Desde el punto de vista nutricional, el caupí es una fuente rica de proteínas, calorías, minerales y vitaminas y, por lo tanto, 


\section{CONGRESO IBÉRICO DE AGROINGENIERÍA \\ X CONGRESSO IBÉRICO DE AGROENGENHARIA \\ 3 - 6 septiembre 2019, Huesca - España}

se considera como un alimento con un alto valor nutricional [7]. Además, es una especie bien adaptada a ambientes estresantes asociados a altas temperaturas, sequías o baja fertilidad, por lo que se considera un cultivo alternativo adecuado en regiones áridas y semiáridas [8].

Por lo tanto, el objetivo de este estudio fue evaluar el efecto de diferentes combinaciones de melón (Cucumis melo) asociado con caupí (Vigna unguiculata) en la producción y calidad de melón, y en el coeficiente de tierra equivalente (LER).

\section{Materiales y métodos}

Este estudio se realizó en el Campo de Cartagena, SE España, con clima mediterráneo semiárido, caracterizado por una temperatura media anual de $18^{\circ} \mathrm{C}$ y una precipitación anual inferior a $300 \mathrm{~mm}$, teniendo una evapotranspiración anual de alrededor de $900 \mathrm{~mm}$.

En este estudio se comparó un monocultivo de melón con diferentes sistemas de cultivo asociado melón-caupí en el verano de 2018: asociado en hileras en relación 1:1 (melón: caupí), asociado en hileras en relación 2:1 (melón:caupí) y cultivo mixtos (donde en una misma fila se alterna melón y caupí).

El experimento de campo se diseñó mediante bloques aleatorios con tres repeticiones, donde cada bloque tenía una superficie de $150 \mathrm{~m} 2$. El monocultivo de melón se realizó en un bloque separado del resto, a $200 \mathrm{~m}$ de distancia de los sistemas asociados para evitar la influencia de la atracción de insectos por el crecimiento del caupí. Las plántulas de melón se sembraron con una densidad de 0,4 plantas $\mathrm{m}-2$, con una separación de $200 \mathrm{~cm}$ entre filas y $120 \mathrm{~cm}$ entre plantas en todas las parcelas (sistemas monocultivos y asociados). Las semillas de caupí se sembraron entre dos hileras de melón en los sistemas asociados, con un espacio de $100 \mathrm{~cm}$ entre las hileras de melón y caupí. En estos sistemas asociados (1:1 y 2:1), el caupí se separó $20 \mathrm{~cm}$ entre plantas en la misma fila. La densidad de las plantas fue de 2.5 plantas m-2 y 1.5 plantas m-2 en los sistemas asociados 1:1 y 2:1, respectivamente. En el sistema mixto, el caupí se sembró en todas las filas de melón, y entre dos plantas de melón, y por lo tanto en una densidad de 0,4 plantas $\mathrm{m}-2$, con un espacio de $200 \mathrm{~cm}$ entre filas y $120 \mathrm{~cm}$ entre plantas. Por lo tanto, la densidad del melón fue la misma en los diferentes tratamientos, mientras que la densidad del caupí cambió.

Todos los cultivos fueron regados por goteo, aplicando $2600 \mathrm{~m} 3 / \mathrm{ha}$, y cultivados bajo manejo orgánico, el cual consistió en la aplicación de un fertilizante ecológico, NORGAN (3.7\% N y 7\% $\mathrm{K} 2 \mathrm{O}$ ), aplicando 3000 1/ha en monocultivo de melón y 2100 1/ha en los asociados/mixto. No se aplicaron herbicidas, mientras que los productos utilizados frente a plagas fueron Breaker, Pirecris, Elosal, y Amicos. En los sistemas asociados, redujimos la tasa de fertilizantes en un $30 \%$ en comparación con el monocultivo. Se incorporaron los residuos del cultivo en los sistemas asociados caupí-melón, con la intención de incorporar los residuos de la leguminosa. El laboreo que se realizó en el monocultivo fue laboreo convencional, mientras que en el asociado se realizó una labor superficial con rotavator (profundidad 15-20 cm).

El melón y el caupí se cosecharon simultáneamente del 31 de julio al 10 de agosto. La cosecha se realizó manualmente como tradicionalmente se realiza en el área de estudio, con el fin de evitar daños en los frutos.

Para calcular la relación de tierra equivalente, se estableció un monocultivo de caupí con 5 plantas m-2, y con un espacio de $100 \mathrm{~cm}$ entre filas y $20 \mathrm{~cm}$ entre plantas, el cual es el patrón tradicional de este cultivo.

\section{Resultados y discusión}

Los resultados indicaron que las distintas combinaciones de cultivos asociados melón-caupí aumentaron significativamente la producción del melón, el número de melones por hectárea y el peso promedio de los mismos (Figura 1). 


\section{CONGRESO IBÉRICO DE AGROINGENIERÍA \\ X CONGRESSO IBÉRICO DE AGROENGENHARIA \\ 3 - 6 septiembre 2019, Huesca - España}

La producción de melón aumentó entre un 34-70\% en comparación con el monocultivo, mientras que la producción de frutos comercializables lo hizo entre el 40-80\%. De este modo, el mejor sistema, desde el punto de vista de la producción, fue la configuración 2:1 y el sistema mixto, con valores de $24759 \mathrm{~kg} \mathrm{ha}^{-1}$ y $26272 \mathrm{~kg} \mathrm{ha}^{-1}$, respectivamente (Figura 1). Los aumentos en la producción de los cultivos se asociaron con aumentos en el número de melones por planta y en su tamaño.

El número de melones por hectárea aumentó hasta los 6556, 7722 y 8278 en el sistema 1:1, en el sistema mixto y en el sistema 2:1, respectivamente, en comparación con los 5605 melones por hectárea en el monocultivo (Figura 1). Esto fue probablemente debido al incremento de los polinizadores en los sistemas asociados. De hecho, se observó que la floración del caupí atrajo una gran cantidad de insectos, muchos de los cuales eran polinizadores. La coincidencia en la floración del caupí con la floración del melón facilitó, de este modo, una mayor tasa de polinización de flores de melón, lo que contribuyó a aumentar el número de melones por planta.
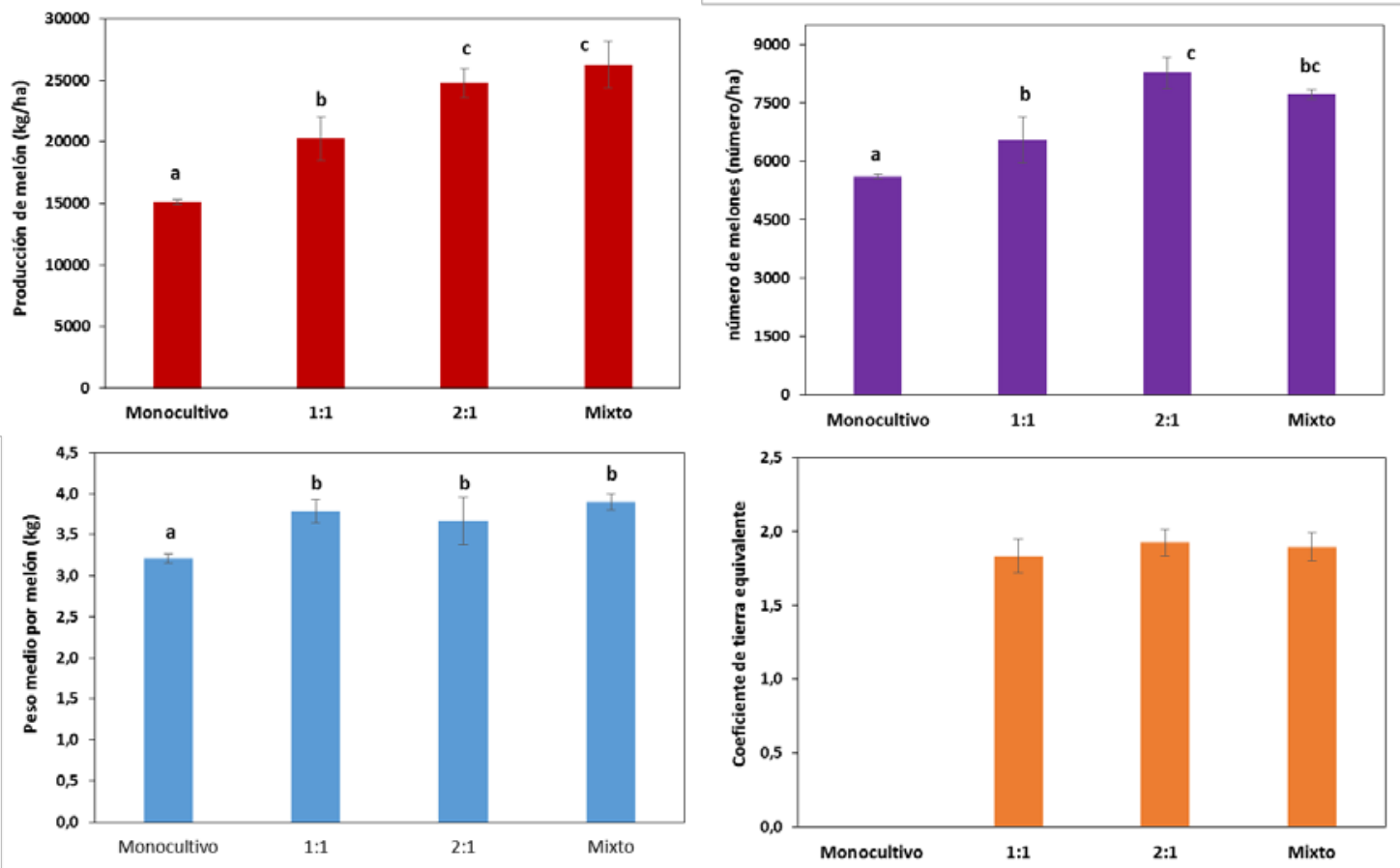

Figura 1. Producción de melón, número de melones, peso promedio de melón y relación de equivalencia de la tierra, de los sistemas de monocultivo e intercalados de melón bajo manejo orgánico. Las barras verticales indican error estándar. Las diferentes letras indican diferencias estadísticamente significativas (post hoc de Tukey $\mathrm{p}<0.05$ ).

De igual modo, el peso de los melones aumentó significativamente en comparación con el monocultivo $(3,21 \mathrm{~kg})$ en todos los sistemas diversificados sin diferencias significativas entre ellos, con valores que oscilan entre 3,70 y $3,90 \mathrm{~kg}$ (Figura 1). Esto podría atribuirse a que el cultivo de caupí tiene una rizosfera muy activa, con una intensa rizodeposición que activa las poblaciones microbianas, con una alta capacidad de movilizar nutrientes del suelo [9]. Además, el caupí también puede fijar nitrógeno atmosférico, lo que contribuye a aumentar la fertilidad del suelo. Estas características probablemente fueron responsables del aumento en el tamaño promedio de los melones en los sistemas asociados, ya que los nutrientes probablemente estaban más biodisponibles.

El coeficiente de tierra equivalente (LER) fue de 1,82; 1,91 y 1,89 para 1:1, 2:1 y cultivos asociados mixtos, respectivamente, destacando el aumento significativo en la productividad de 


\section{CONGRESO IBÉRICO DE AGROINGENIERÍA \\ X CONGRESSO IBÉRICO DE AGROENGENHARIA \\ 3 - 6 septiembre 2019, Huesca - España}

la tierra cuando se asocia el melón con el caupí. Esto fue debido tanto al aumento del rendimiento de melón en los sistemas de cultivo asociados, como a la producción adicional de caupí.

Finalmente, que no se observaron diferencias significativas en los parámetros de calidad del melón, excepto por el contenido de azúcar, que fue ligeramente mayor en los melones monocultivos $\left(13,1^{\circ}\right.$ Brix $)$, en comparación con los sistemas asociados $\left(12,4-12,6^{\circ}\right.$ Brix).

\section{Conclusiones}

Este estudio permite afirmar que la introducción de caupí en cultivos asociados con melón aumenta la producción del cultivo principal, tanto el número de frutos y su tamaño de los mismos se vieron incrementados significativamente, esto fue principalmente debido a una mayor polinización de las flores de melón favorecida por la floración del caupí, la cual atrajo a un mayor número de insectos polinizadores. No obstante, en futuros ciclos se evaluará con mayor detalle la presencia de estos insectos beneficiosos con el fin de contrastar esta hipótesis con datos objetivos y cuantitativos.

De igual modo, la asociación melón-caupí permitió reducir el uso de insumos externos ( $30 \%$ la fertilización), al mismo tiempo que el coeficiente de tierra equivalente casi se duplicó, no observándose diferencias en la calidad de los frutos.

Por lo tanto, se puede concluir que la asociación melón-caupí podría ser una alternativa sostenible a los sistemas de producción tradicionales en monocultivo, lo cual será corroborado mediante la evaluación de varios ciclos de cultivo.

\section{Agradecimientos}

La realización de este trabajo ha sido posible gracias a la financiación del Ministerio de Economía y Competitividad y el Fondo Europeo de Desarrollo Regional (FEDER) mediante el proyecto ASOCIAHORTUS (AGL2017-83975-R).

\section{Referencias}

1. Sawada H., Kuykendall L.D., Young J.M. Changing concepts in the systematics of bacterial nitrogenfixing legume symbionts. The Journal of General and Applied Microbiology. 2003, 49, 155-179.

2. Drinkwater, L.E., Wagoner, P., Sarrantonio M. Legume-based cropping systems have reduced carbon and nitrogen losses. Nature. 1998, 396, 262-265.

3. St Luce M., Grant C.A., Zebarth B.J., Ziadi N., O'Donovan J.T., Blackshaw R.E., Harker K.N., Johnson E.N., Gan Y., Lafond G.P., May W.E., Khakbazan M., Smith E.G. Legumes can reduce economic optimum nitrogen rates and increase yields in a wheat-canola cropping sequence in western Canada. Field Crops Research, 2015, 179, 12-25.

4. Lupwayi N.Z., Kennedy A.C. Grain legumes in Northern Great plains: impacts on selected biological soil processes. Agronomy Journal 2007, 99, 1700-1709

5. Munier-Jolain N. The long-term impact of grain legumes on the environment: possibilities for reducing herbicides. Grain. Legumes. 2002, 36, 16-17.

6. Singh B.B. Cowpea: The Food Legume of the 21st Century. Crop Science Society of America. 2014.

7. Deshpande S.S. Food legumes in human nutrition: a personal perspective. Food Sciencie and Nutricion 1992, 32, 333-363.

8. Chikoye D., Abaidoo R., Fontem L.A. Response of weeds and soil microorganisms to imazaquin and pendimethalin in cowpea and soybean. Crop Protection 2014, 65, 168-172.

9. Sánchez-Navarro V., Zornoza R., Faz A., Fernández J.A. Comparing legumes for use in multiple cropping to enhance soil organic carbon, soil fertility, aggregates stability and vegetables yields under semiarid conditions. Science Horticulturae 2019, 246, 835-841. 